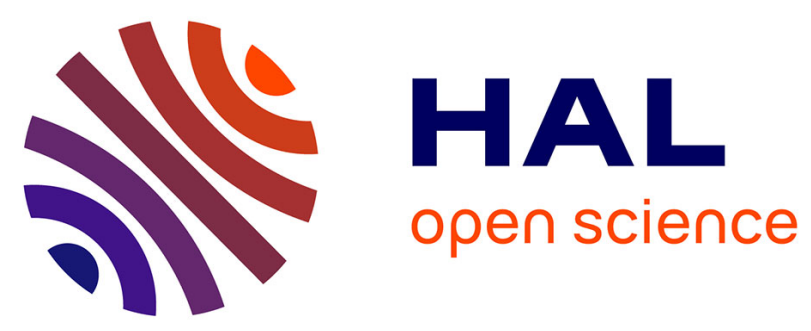

\title{
Investigation of the Protonation Site in the Dialanine Peptide by Infrared Multiphoton Dissociation Spectroscopy
}

Bruno Lucas, Gilles Grégoire, Joël Lemaire, Philippe Maître, Jean-Michel Ortega, Alisa Rupenyan, Bernd Reimann, Jean Pierre Schermann, Charles

Desfrançois

\section{To cite this version:}

Bruno Lucas, Gilles Grégoire, Joël Lemaire, Philippe Maître, Jean-Michel Ortega, et al.. Investigation of the Protonation Site in the Dialanine Peptide by Infrared Multiphoton Dissociation Spectroscopy. Physical Chemistry Chemical Physics, 2004, 6, pp.2659. 10.1039/b316053j . hal-00002342

\section{HAL Id: hal-00002342 https://hal.science/hal-00002342}

Submitted on 27 Jul 2004

HAL is a multi-disciplinary open access archive for the deposit and dissemination of scientific research documents, whether they are published or not. The documents may come from teaching and research institutions in France or abroad, or from public or private research centers.
L'archive ouverte pluridisciplinaire HAL, est destinée au dépôt et à la diffusion de documents scientifiques de niveau recherche, publiés ou non, émanant des établissements d'enseignement et de recherche français ou étrangers, des laboratoires publics ou privés. 


\title{
Investigation of the Protonation Site in the Dialanine Peptide by Infrared Multiphoton Dissociation Spectroscopy
}

\author{
Bruno Lucas ${ }^{1}$, Gilles Grégoire ${ }^{1}$, Joël Lemaire ${ }^{2}$, Philippe Maître ${ }^{2}$, Jean-Michel Ortega ${ }^{3}$, \\ Alisa Rupenyan ${ }^{1}$, Bernd Reimann $^{1}$, Jean Pierre Schermann ${ }^{1}$ and Charles Desfrançois ${ }^{1 *}$ \\ ${ }^{1}$ Laboratoire de Physique des Lasers, UMR7538 CNRS, Institut Galilée, Université Paris-Nord, \\ F-93430 Villetaneuse, France \\ ${ }^{2}$ Laboratoire de Chimie Physique, UMR8000 CNRS, Bat.350, Université Paris XI, \\ F-91405 Orsay Cedex, France \\ ${ }^{3}$ CLIO-LURE, UMR130 CNRS-CEA, Bat. 209D, Université Paris XI, \\ F-91405 Orsay Cedex, France
}

\begin{abstract}
Protonated dialanine cations have been isolated in a Fourier transform ion cyclotron resonance mass-spectrometer (FT-ICR-MS) and subjected to infrared multiphoton dissociation (IRMPD) at the free electron laser facility CLIO in Orsay (France). The spectral dependence of the IR induced fragmentation pattern in the mid-infrared region $\left(800-2000 \mathrm{~cm}^{-1}\right)$ is interpreted with the help of structure and vibrational spectrum calculations of the different protonated conformers. This comparison allows for the assignment of the proton on the terminal amino group, as the most favourable proton site, the neighbouring amide bond being in the trans conformation.
\end{abstract}




\section{Introduction}

Identification of proteins is routinely performed by means of mass-spectrometry. Following proteolysis, a tryptic digest peptide fragment can be introduced in the gas phase and ionised, either by means of electrospray ionisation (ESI) or by matrix assisted laser desorption ionisation (MALDI), and then submitted to fragmentation. The peptide fragment mass-fingerprint then leads to the protein primary sequence. Collision induced dissociation (CID) is a very efficient process for deposition of energy in an isolated peptide cation leading to its fragmentation ${ }^{1-5}$. According to the peptide cation sequence, different fragmentation patterns are observed and several authors have contributed to the development of a "mobile proton model" which aims to explain those cleavage patterns ${ }^{6-8}$. In this model, it is assumed that before energy deposition, a proton is tightly bound by the peptide in its lowest energy configuration at a basic site (e.g. at the N-terminal or on a sidechain). Following excitation, the proton then explores different excited configurations that become populated and cleavage takes place once it is located on a backbone site. For example, as recently reviewed in reference ${ }^{9}$, different ( $b$ or $y$ ) cations are produced whether the positive charge remains on the $\mathrm{N}$ terminal fragment or on the $\mathrm{C}$ terminal. Understanding gas-phase dissociation mechanisms is useful for improving procedures which are used in peptide sequencing and protein identification by means of mass spectrometry ${ }^{7}$.

It has recently been shown that gas-phase conformations can strongly influence peptide fragmentation ${ }^{10}$. We here consider a method that provides enough energy to induce protonated peptide fragmentation and that leads to structural information about the initial intact gas-phase peptide cations. Those protonated ions, produced by MALDI, are first stored and mass-selected in a Fourier transform ion cyclotron resonance mass spectrometer (FT-ICR-MS). They are further submitted to infrared multiphoton dissociation (IRMPD) and the fragment ion yields are recorded as a function of the IR excitation energy ${ }^{11}$. IRMPD requires the use of a laser source of high peak fluence of infrared photons, which can be tuned over the different vibrational absorption lines. A high repetition rate is also required for multiple photon absorption leading to dissociation during ion trapping times. These conditions are well fulfilled by infrared free electron lasers (FEL) as recently demonstrated at FELIX ${ }^{12}$ and CLIO ${ }^{11}$.

Some important points must be stressed concerning this technique. Although cations are produced by MALDI, at high internal energies of about $1500 \mathrm{~K}$, they are trapped in the ICR cell during few seconds ( $2 \mathrm{~s}$ in the present experiments) before exposure to the IR radiation. Thus, they have enough time to substantially relax towards room temperature, as it has been shown by the extensive work of Dunbar et al. on the radiative relaxation time constants for cations of similar size 
and similar initial excess internal energies ${ }^{13}$. In the present IRMPD experiments, the first IR photon is then absorbed by cations that present a low density of vibrational states. This first step is resonant and its spectral dependence is thus characteristic of the initial cation conformations at room temperature, as usual in IR absorption spectroscopy. This first amount of added energy is then rapidly redistributed over the different coupled modes and further absorption of IR photons leads to fragmentation, due to progressive heating, in a very similar fashion as compared to multiple collision activation (MCA-CID) ${ }^{1-5}$. Direct absorption infrared spectroscopy of cations would be very difficult due to the extremely small ion densities obtainable in mass spectrometers and one here takes advantage of the high sensitivity of fragment ion detection in FT-ICR-MS, in order to monitor the first resonant step. However, one should not expect a perfect matching between observed and calculated spectral fragmentation patterns. For calculating fragmentation spectra, it is assumed for simplicity that only the resonant initial excitation step has to be taken into account. While absorption frequencies can be determined with a reasonable accuracy by means of DFT (Density Functional Theory), which is the most accessible method for such mid-size molecular systems, intensities are not so well predicted ${ }^{14}$. Moreover, for fragmentation, this first step is necessarily followed by multiple absorption within a quasi-continuum where vibrational transitions can be slightly red-shifted and broadened due to anharmonic couplings 15 .

Up to now, different methods have been used for the determination of protonation sites of peptides. Experimentally, one can study deprotonation reactions of investigated peptides by reference compounds 16 or hydrogen/deuterium exchange reactions ${ }^{17}$. Those studies are usually complemented by quantum chemistry calculations, which provide low-energy equilibrium structures and protonation energetics 3, 6. In the present work, we would like to show that IR spectroscopy can also bring valuable information on the protonation sites of peptides ions, isolated in the gas-phase and close to thermal equilibrium at room temperature. The results reported here concern the protonated dialanine cation, Ala-Ala- $\mathrm{H}^{+}$, which fragmentation pattern has been thoroughly studied, in MCA-CID experiments 1, 4. This cation already possesses several conformers, similar to those encountered in larger protonated peptides, with different protonation sites. However, its small size (24 atoms), and its very simple methyl side-chains, allows for a rather easy exploration of its whole potential energy surface (PES), with still simple computational means. We also take advantage of the detailed theoretical study of the very similar protonated diglycine, previously performed by Suhai et al. ${ }^{6,8}$. After a description of the experimental procedure, spectral dependences of IRMPD fragmentation yields will be discussed with the help of calculation of the different AlaAla- $\mathrm{H}^{+}$cation structures and their simulated vibrational spectra. 


\section{Experimental}

IRMPD of AlaAla- $\mathrm{H}^{+}$cations has been studied in a home-built compact FT-ICR-MS, MICRA, which has been described in detail elsewhere 18. This spectrometer has a permanent magnet producing a magnetic field of 1.25 Tesla, allowing for a mass-range of 10 to $1000 \mathrm{amu}$, and its mass-resolution is better than 30000 at mass 161 of the studied cations. Those AlaAla- $\mathrm{H}^{+}$ cations were produced by a MALDI technique: racemic dialanine (DL-Ala-DL-Ala from Aldrich) was mixed with alpha-cyano-4-hydroxycinnamic acid (CHCA) as the matrix, in a 1:1 mass ratio, and compressed into a $1 \mathrm{~mm}$ thick pellet. A $4 \times 4 \mathrm{~mm}$ piece of this pellet was then glued on a steel holder, which was mounted just outside the ICR, $6 \mathrm{~mm}$ away from a trapping plate. The cations entered the ICR cell collinearly with the magnetic field through a $5 \mathrm{~mm}$ diameter hole. The target holder was maintained at $1.8 \mathrm{~V}$, while a $3.5 \mathrm{~V}$ potential was applied to the trapping plates, so as to optimise the ion signals. Furthermore, synchronised with the pulsed laser output at the YAG third harmonic wavelength, the potential of the entrance trapping plate was pulsed down to $0 \mathrm{~V}$ for about $25 \mu \mathrm{s}$, in order to allow for ion entrance into the cell. As outlined above, these cations initially possess a large amount of internal energy and thus fragment. They were thus allowed to internally relax, close to room temperature, either by collisions with the background gas (few $10^{-8}$ Torr) or by radiative decay, during 2 seconds. Cations with the mass of interest, i.e. $161 \mathrm{amu}$, were then massselected, by ejection of all other ions, before IR irradiation.

Fragmentation was then resonantly induced by IRMPD. The electron accelerator of the FEL CLIO facility was set at $44 \mathrm{MeV}$ and a continuously tuneable laser beam was obtained between 800 and $2000 \mathrm{~cm}^{-1}$ with a bandwidth of about $10 \mathrm{~cm}^{-1}$. A train of 25 macropulses per second was sent into the trap during 2 seconds after cation selection. One macropulse contained 500 micropulses, each of them of few picoseconds duration, separated by $16 \mathrm{~ns}$. During the present experiments, the measured mean laser power was stable around $800 \mathrm{~mW}$, at $9 \mu \mathrm{m}$, thus corresponding to $32 \mathrm{~mJ}$ per macropulse or $64 \mu \mathrm{J}$ per micropulse. At $5 \mu \mathrm{m}$, the laser power was only $380 \mathrm{~mW}$. However, in the present experiments, this FEL beam was attenuated by a factor of 3, using one attenuator, in order to avoid saturation. The laser beam entered the vacuum chamber perpendicular to the magnetic field through a ZnSe window. It was mildly focussed with a one-meter focal length spherical mirror and the beam waist was estimated to be about $0.3 \mathrm{~mm}$ at $5 \mu \mathrm{m}$, i.e. smaller than the size of the ion cloud 18. Considering the variation of the waist as a function of the laser wavelength, the IR fluence can be estimated to be about the same from 5 to $9 \mu \mathrm{m}$. Thus, considering the complex multiphoton character of the IRMPD process, no fluence correction has been applied and the raw IRMPD spectra are here provided and compared to calculated absorption spectra. 


\section{Results and discussion}

The observed mass spectra are very simple and similar to those obtained in the high-pressure regime of CID experiments 1, which corresponds to multiple-collision activation. Before IR irradiation or for a FEL wavelength outside the absorption bands, the main peaks correspond to mass 161, i.e. intact protonated dialanine, and to masses 189, 172 and 146, i.e. parent and fragment cations from the CHCA matrix. Another small peak corresponds to mass 44, i.e. the well-know immonium $\mathrm{a}_{1}$ ion $\mathrm{H}_{2} \mathrm{~N}^{+}=\mathrm{CH}-\mathrm{CH}_{3}$ that is always observed for alanine-containing peptide ${ }^{1}$. Two other small peaks appear at masses 70 and 187, corresponding to masses 44 and 161 plus an additional mass 26. When IRMPD occurs, no spectral fingerprint is observed for any of these ions except for the parent (161) and immonium fragment (44) ions. The former displays spectral depletion that corresponds to a simultaneous increase of the fragment signals. We thus here present the fragmentation yield as corresponding to mass 44 fragment signals divided by the sum of the fragment and parent cation signals, as plotted as a function of the FEL photon energy in Fig. 1. This spectrum is dominated by three groups of absorption bands: a first one with two peaks at 1130 and $1170 \mathrm{~cm}^{-1}$, a second one with several peaks at 1375, 1400, 1460 and $1525 \mathrm{~cm}^{-1}$, and a last double peak at 1700 and $1760 \mathrm{~cm}^{-1}$. Despite the laser attenuation, the fragmentation yield is quite high and amounts up to $60 \%$ for the first peaks. From the shape of the first and the last three peaks, it can be estimated that the full width at half maximum (FWHM) is about $40 \mathrm{~cm}^{-1}$, for each individual absorption line. A similar bandwidth had been obtained in the case organometallic complexes ${ }^{11}$, protonated benzene ${ }^{19}$ and sodiated amino acids ${ }^{15}$, which were recorded with a similar experimental procedure. Since the laser bandwidth is only about $10 \mathrm{~cm}^{-1}$, this experimental line width is probably mainly due to the rotational bandwidth of the ions at room temperature, as it is observed for similar neutral molecular species in the gas phase ${ }^{20}$. However, we cannot exclude some additional broadening due to some remaining saturation or due to the multiphoton process.

Infrared absorption spectra of different low-lying energy configurations of the AlaAla- $\mathrm{H}^{+}$ cation have been calculated in order to assign the IRMPD fragmentation patterns. As already stated above, different sites are available for the excess proton and several conformations must be considered for each of them. An exploration of the PES of the protonated dialanine cation has been carried out using the conformational search algorithm implemented in HyperChem 7.0 (Hypercube Inc.). We here use the same nomenclature as in the study of protonated diglycine ${ }^{6}$. The site of protonation is indicated by A for the $\mathrm{N}$-terminal amino group or $\mathrm{O}$ for the carbonyl oxygen of the amide $\mathrm{C}=\mathrm{O}$ group. We here consider only $\mathrm{A}$ and $\mathrm{O}$ protonation sites since the PES of protonated dialanine is expected to be very similar to that of protonated diglycine, as calculated by Suhai et al. 
6. In this case, conformers protonated at the nitrogen atom of the amide group (D) and diol-like conformers $(\mathrm{G})$, originating from protonation at the acidic $\mathrm{C}=\mathrm{O}$ group, lie more than $10 \mathrm{kcal} / \mathrm{mole}$ above the $\mathrm{A}$ and $\mathrm{O}$ conformers and are thus very unlikely to be populated at $300 \mathrm{~K}$. We indeed calculated that the lowest D conformer lies more than $12 \mathrm{kcal} / \mathrm{mol}$ above the most stable conformer in the present dialanine case.

The conformational search was performed at the AM1 semi-empirical level. For both A and $\mathrm{O}$ isomers, we explored the PES along all the torsion (dihedral) angles of the peptide backbone and the $\mathrm{O}-\mathrm{H}$ bond orientations. About 20 local minima, lying within $10 \mathrm{kcal} / \mathrm{mol}$ above the absolute minimum, were selected as starting points for full structure optimisations at the hybrid density functional B3LYP/6-31G* level, using the Gaussian 03 package ${ }^{21}$. Subsequent (harmonic) frequency calculations were also performed, in order to check for actual minima and to obtain the corresponding IR frequencies. Calculated relative energies of the lowest conformers, including the zero-point-energy (ZPE) and the thermal energy at $298 \mathrm{~K}$, are provided in Table 1 together with the energies relative to the most stable A1 conformer. In order to check for the validity of the present calculation level, we also performed single point B3LYP/6-31++G** energy calculations, at the B3LYP/6-31G* geometry. The results are also given in Table 1 for the eleven most stable conformers. With these larger basis set calculations, the corresponding relative energetics of the low-lying conformers do not change much and are always within $0.7 \mathrm{kcal} / \mathrm{mol}$ with respect to B3LYP/6-31G* results. In the following, we will thus refer only to these results. We also give the backbone $(\Psi, \omega, \phi)$ and $\mathrm{OH}(\alpha, \beta)$ orientation torsion angle values that have been used in the conformational search, again with the same nomenclature as in the diglycine study ${ }^{6}$. Fig. 2 displays the four lowest calculated equilibrium structures of AlaAla- $\mathrm{H}^{+}$. Among the lowest-energy conformers, A1/A2/A3 and O1/O2/O3 conformers are similar, in geometry and in relative energies, to those calculated for protonated diglycine ${ }^{6}$. In particular, they correspond to a trans conformation of the amide bond, i.e. $\omega$ values close to $180^{\circ}$. However, for each of them, we found some additional minima, denoted in Table I by " or " symbols, which correspond to some variations in the torsion angles. More importantly, we also found additional minima corresponding to a cis conformation of the amide bond, i.e. $\omega$ values close to $0^{\circ}$. These equilibrium structures were not considered for the protonated diglycine ion although one of them, the cis 33 conformer in the present study, lies only $1.63 \mathrm{kcal} / \mathrm{mol}$ above the lowest conformation A1. We must however outline that the trans-cis isomerisation is highly improbable since the corresponding barrier is expected to be very high. We indeed calculated that the barrier height between trans $\mathrm{A} 1$ and $\operatorname{cis} \mathrm{A} 3$ conformers is more than $1 \mathrm{eV}(24.2 \mathrm{kcal} / \mathrm{mol})$. For comparison, the calculated barrier height values, for the trans conformations, are only $3.2 \mathrm{kcal} / \mathrm{mol}$ between $\mathrm{A} 1$ and $\mathrm{O} 1$ and $2.5 \mathrm{kcal} / \mathrm{mol}$ between $\mathrm{A} 1$ and A2. In 
the matrix, dialanine molecules are expected to be initially in the regular trans conformation. When produced by MALDI, protonated ions are created with high internal energies, typically of about kT $\sim 3 \mathrm{kcal} / \mathrm{mol}$ per mode at an estimated temperature of about $1500 \mathrm{~K}$. From the above isomerisation barriers, it is thus expected that only trans ion conformations can be formed. After being cooled down close to $300 \mathrm{~K}$, the mean cation internal energy per mode is decreased to $\mathrm{kT} \sim 0.6 \mathrm{kcal} / \mathrm{mol}$ and the relevant energetic quantities are the free energies. The present calculated (harmonic) free energy differences with respect to $\mathrm{A} 1$ are $2.21 \mathrm{kcal} / \mathrm{mol}$ for $\mathrm{O} 1$ and $1.59 \mathrm{kcal} / \mathrm{mol}$ for $\mathrm{A} 2$ conformers. From the above isomerisation barriers and energy differences, it is thus expected that the trans conformer populations should be in the order A1 >> A2 > O1. Other conformers lie at too high energies (about $3 \mathrm{kcal} / \mathrm{mol}$ or more, with respect to A1) to be noticeably present at room temperature. These theoretical predictions are discussed below from the comparison between the experimental spectrum and the simulated spectra.

For the four lowest calculated conformers, A1 cisA3 O1 and A2, the corresponding predicted IR absorption spectra in the $800-2000 \mathrm{~cm}^{-1}$ range are presented in Fig. 3. Those simulated spectra have been obtained by using the regular scaling factor of $.9614^{22}$, for the calculated harmonic vibrations at the present level of theory. Furthermore, calculated stick spectra have been convoluted with a $40 \mathrm{~cm}^{-1}$ wide (FWHM) Lorentzian profile, in order to better simulate the experimental spectrum. The comparison between those simulated spectra and the experimental spectrum leads us to the conclusion that the observed conformer must correspond mainly to a trans A geometry. The best fit to the experimental spectrum indeed corresponds to conformer trans A1, while conformer trans A2 also matches quite well. In those cases, the theoretical line positions correspond nicely to peaks in the IRMPD absorption spectrum, particularly in the region above $1300 \mathrm{~cm}^{-1}$, while A1 appears to perform slightly better than A2 in the region 1000-1200 $\mathrm{cm}^{-1}$. However, in both cases and at least below $1500 \mathrm{~cm}^{-1}$, the line intensities are clearly not as good as the line positions. These discrepancies in the line intensities could be due either to the rather rough theoretical method employed here or, as discussed in the introduction, to the IRMPD process itself. The cisA 3 conformer can be clearly ruled out. First, it displays only one intense peak at $1725 \mathrm{~cm}^{-1}$ instead of two at 1700 and $1760 \mathrm{~cm}^{-1}$ in the experimental spectrum. Second, this conformer spectrum does not display any intense peak around $1525 \mathrm{~cm}^{-1}$ whereas a quite large IRMPD fragmentation is observed at this energy. The trans $\mathrm{O} 1$ conformer can also be ruled out because of the discrepancies again at $1700 \mathrm{~cm}^{-1}$, where two peaks are present but too much separated at 1680 and $1760 \mathrm{~cm}^{-1}$. Furthermore, around $1400 \mathrm{~cm}^{-1}$, calculated absorption bands are much too weak as compared to the experimental data. We have also checked that, for the following higher energy conformers, such, or even worse, discrepancies are observed. We can thus conclude that, in protonated dialanine, protonation occurs on the terminal amino group, corresponding either to the 
trans A1 or the transA2 conformers. This is in good agreement with the above theoretical predictions, from the calculated conformer energetics. However, only more refined calculations and better-resolved experimental data could bring more information on all conformer populations at room temperature.

\section{Summary and conclusions}

From the IRMPD spectrum of the protonated dialanine cation, as compared to standard quantum chemistry calculations, we conclude that the favoured protonation site is the terminal amino group, at least at low internal energies close to room temperature. We found that the IRMPD spectrum matches with those of the two low-energy conformers corresponding to this protonation site. These two conformers were predicted to be within the four lowest energy isomers of the system and, for both of them, the adjacent amide bond is in the regular trans conformation. The lowest energy conformer A1 corresponds to an almost planar geometry of the peptide backbone (all torsion angles close to $180^{\circ}$ ). It differs from the second one $\mathrm{A} 2$ in only one torsion angle, the $\mathrm{C}_{\text {amide- }}$ $\mathrm{N}-\mathrm{C}-\mathrm{C}_{\text {acid }}$ dihedral angle that is close to $90^{\circ}$, leading the acidic group to be almost perpendicular to the beginning of the peptide backbone. From this comparison and from the calculated energetics, it is concluded that all others conformers, such as cis conformations of the amide bond or protonation sites on the amide oxygen, do not noticeably contribute to the experimental IR spectrum.

Additional information, obtained from other parts of the IR spectrum, and more refined energetic and frequency calculations of the low-lying equilibrium structures, may help to obtain a more quantitative agreement between the calculated and experimental spectra. It seems that the present technique may be limited to relatively small systems (several tens of atoms) so that only few low-energy conformers contribute to the experimental spectrum, which can still retain some characteristic sharp features, and so that accurate quantum chemistry calculations can still be performed, over the whole low-energy part of the PES. The IRMPD technique is however a unique tool to study the main structures of isolated molecular or complex ions of biological interest, a welldefined thermodynamic temperature. The comparison with theoretical calculations is made much easier than for condensed phase data, because of the absence of solvent effects. Other data obtained on different small protonated peptides will be reported soon and future experiments should also concern negative ions such as nucleotides or sulfated monosaccharides. 
Table 1: Energetic and geometrical parameters for the lowest-energy conformers of Ala-Ala- $\mathrm{H}^{+}$. Relative electronic energies corrected from ZPE $\left(\Delta \mathrm{E}_{\mathrm{ZPE}}\right.$ at $\left.0 \mathrm{~K}\right)$ and relative electronic plus thermal energies at $298 \mathrm{~K}\left(\Delta \mathrm{E}_{298}\right)$ are calculated at the $\mathrm{B} 3 \mathrm{LYP} / 6-31 \mathrm{G}^{*}$ level and are given with respect to most stable conformer transA1 $\left(\mathrm{E}_{\mathrm{ZPE}}=-571.239519\right.$ Hartree and $\mathrm{E}_{298}=-571.227128$ Hartree). For the lowest conformers, we also give the results of single point energies calculated at the B3LYP/6-

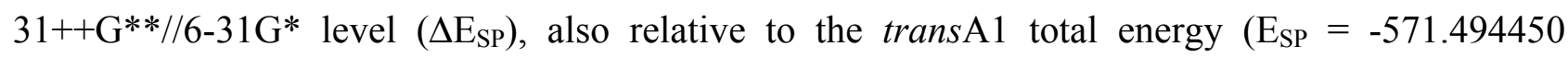
Hartree). The torsion angles are also given (see text for nomenclature) for all displayed conformers. Other conformers, located higher than $10 \mathrm{kcal} / \mathrm{mol}$ above trans $\mathrm{A} 1$, have been omitted, as for all D and $\mathrm{G}$ conformers.

\begin{tabular}{|c|c|c|c|c|c|c|c|c|c|}
\hline Conformer & $\begin{array}{c}\Delta \mathrm{E}_{\mathrm{ZPE}} \\
(\mathrm{kcal} / \mathrm{mol})\end{array}$ & $\begin{array}{c}\Delta \mathrm{E}_{298} \\
(\mathrm{kcal} / \mathrm{mol})\end{array}$ & $\begin{array}{c}\Delta \mathrm{E}_{\mathrm{SP}} \\
(\mathrm{kcal} / \mathrm{mol})\end{array}$ & $\psi_{1}\left(^{\circ}\right)$ & $\omega\left(^{\circ}\right)$ & $\phi\left(^{\circ}\right)$ & $\psi_{2}\left({ }^{\circ}\right)$ & $\alpha\left(^{\circ}\right)$ & $\beta\left(^{\circ}\right)$ \\
\hline transA1 & 0 & 0 & 0 & 175.6 & 177.2 & -162.1 & 173.7 & 178.7 & \\
\hline cisA3 & 1.63 & 1.40 & 1.75 & 128.8 & -25.8 & -54.1 & -154.5 & -177.4 & \\
\hline transO1 & 1.73 & 1.59 & 1.20 & 180.0 & 180.0 & -164.3 & 173.2 & 178.7 & 0.0 \\
\hline transA2 & 1.73 & 1.81 & 1.52 & 165.9 & 161.9 & -74.3 & 177.8 & 180.0 & \\
\hline transO2 & 3.15 & 2.94 & 2.49 & -4.0 & 168.8 & 46.4 & 145.2 & 175.0 & 168.0 \\
\hline trans $\mathrm{O} 2$ & 3.70 & 3.48 & 3.20 & -3.1 & -167.2 & -55.3 & -140.2 & -175.8 & -164.4 \\
\hline transA3 & 3.74 & 3.54 & 3.37 & -120.0 & 141.9 & -61.1 & -178.7 & -179.1 & \\
\hline transA3' & 4.00 & 3.83 & 3.95 & 113.1 & -141.9 & 57.8 & 180.0 & -178.6 & \\
\hline transA2' & 4.07 & 4.08 & 3.71 & 165.1 & -165.3 & 62.0 & 180.0 & -178.6 & \\
\hline transO3 & 4.13 & 4.10 & 3.39 & 176.5 & 168.8 & -71.5 & 180.0 & 180.0 & 1.7 \\
\hline transA1' & 4.35 & 4.43 & 4.17 & 173.6 & 177.4 & -153.0 & -11.7 & -177.5 & \\
\hline transO1' & 6.17 & 6.15 & & 178.9 & 180.0 & -154.5 & -13.7 & -177.6 & 0.0 \\
\hline cisO3 & 6.37 & 6.22 & & 169.2 & -15.3 & -65.4 & -164.4 & -177.6 & 6.5 \\
\hline transO3' & 6.37 & 6.27 & & 178.0 & -169.0 & 62.7 & 177.8 & -179.1 & 1.5 \\
\hline transA2" & 6.50 & 6.57 & & 170.8 & -178.5 & 58.0 & 30.2 & 176.0 & \\
\hline cisA3' & 7.88 & 7.67 & & 129.2 & -28.3 & -53.2 & -153.3 & 6.5 & \\
\hline transO5 & 8.41 & 8.58 & & -9.7 & 180.0 & -161.4 & 172.1 & 178.6 & -2.3 \\
\hline cisA1-2 & 8.49 & 8.42 & & 152.3 & -29.1 & 71.9 & 140.0 & 175.8 & \\
\hline transO3" & 8.73 & 8.69 & & 178.0 & -177.4 & 59.0 & 26.5 & 176.3 & 0.8 \\
\hline transO2" & 9.02 & 8.95 & & -3.8 & -170.2 & -71.3 & 67.3 & 180.0 & -164.6 \\
\hline transA3" & 9.43 & 9.24 & & -119.8 & 140.5 & -59.7 & 177.8 & -0.9 & \\
\hline transO7 & 9.70 & 9.84 & & -10.0 & 172.7 & -69.9 & -177.7 & 180.0 & -3.6 \\
\hline
\end{tabular}


Figure 1: Fragmentation yield of protonated dialanine cations, for mass 44 fragments, as a function of the FEL energy.

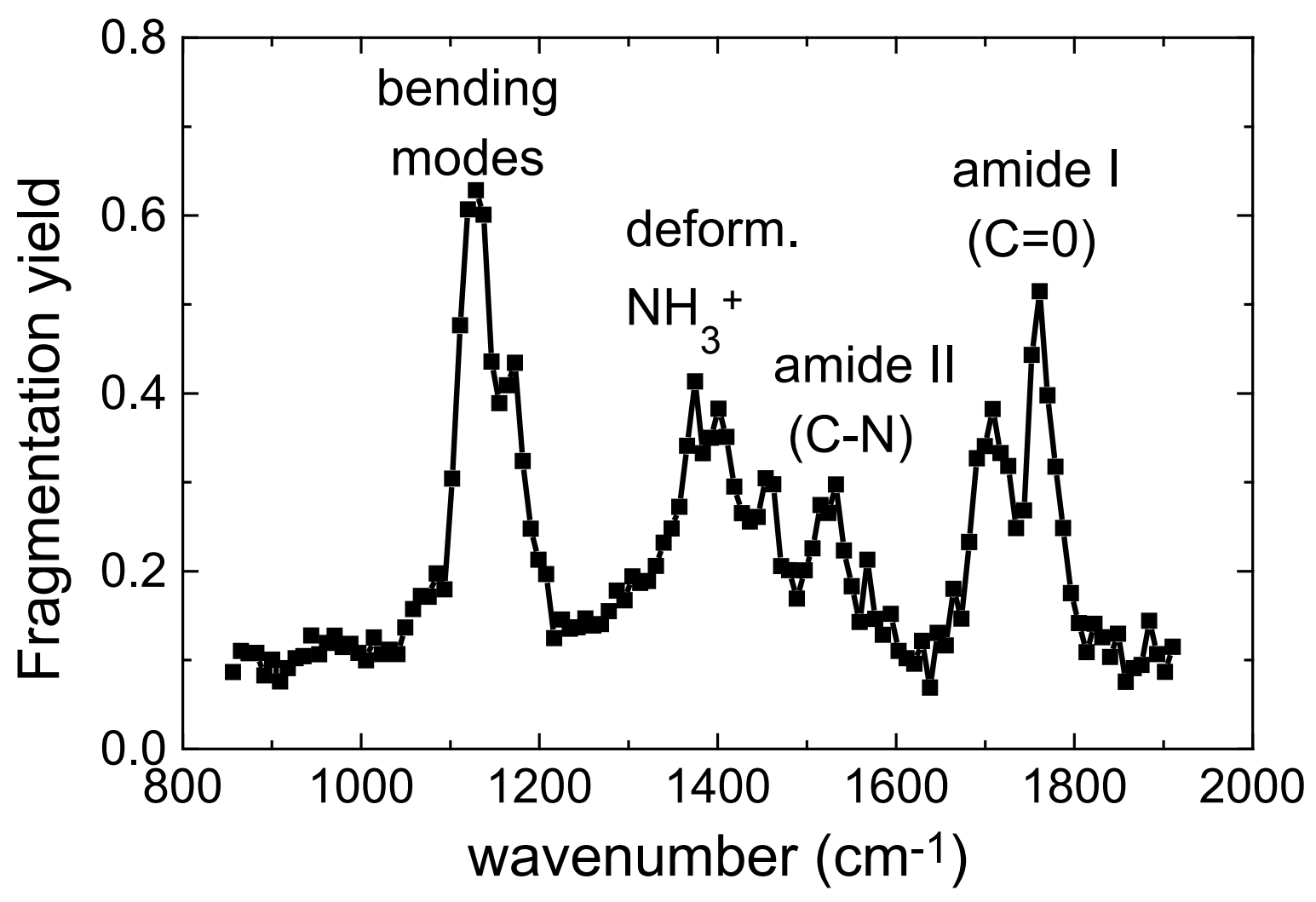


Figure 2: Lowest-energy structures of protonated dialanine.

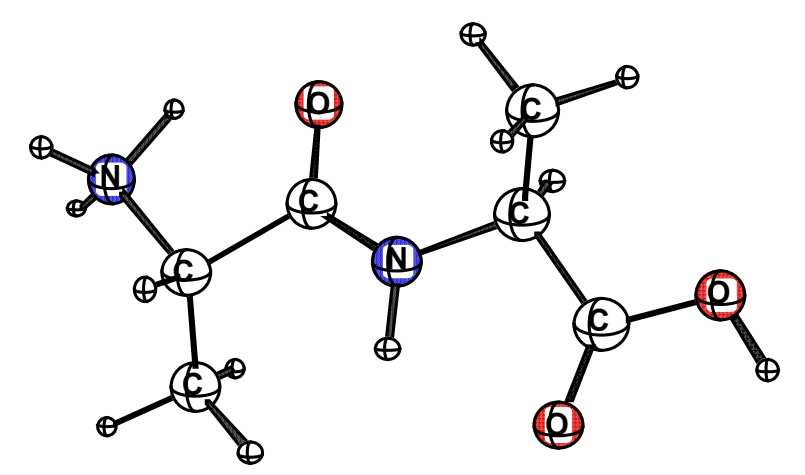

Trans A1

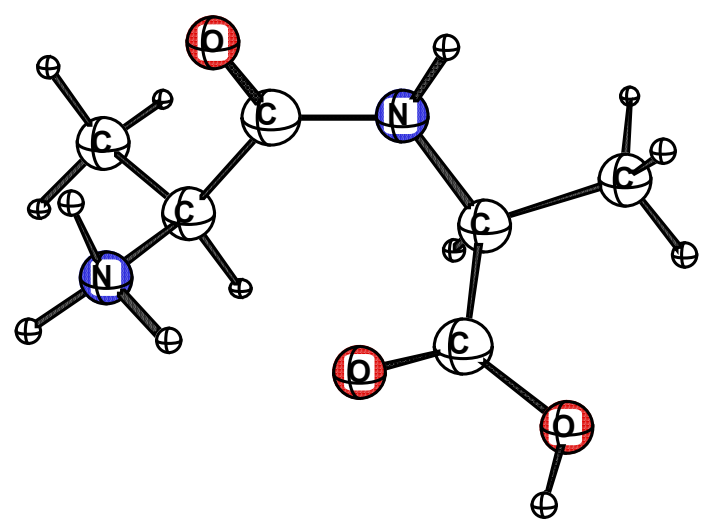

Cis A3

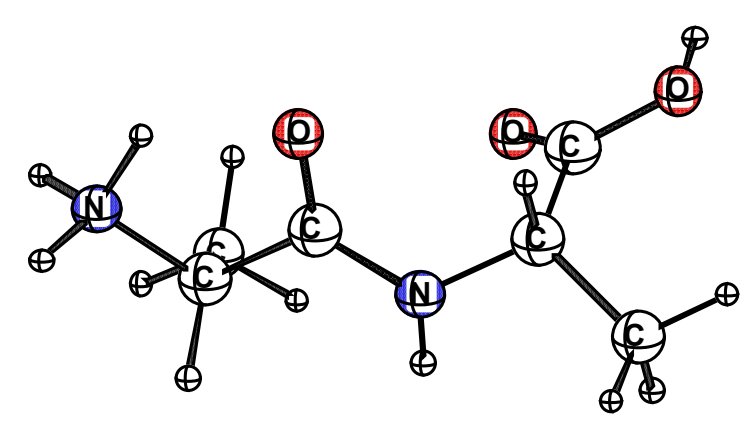

Trans A2

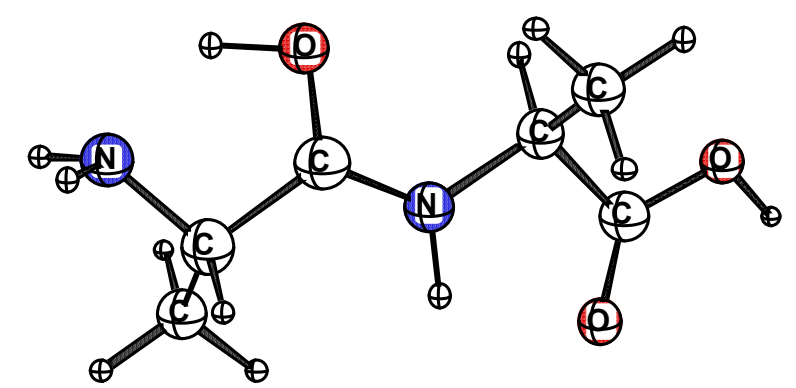

Trans 01 
Figure 3: Comparison between the calculated IR spectra, for the four lowest AlaAla- $\mathrm{H}^{+}$calculated conformers of Fig. 2, and the experimental spectrum. Stick spectra correspond to scaled harmonic frequencies and intensities are such that 1 on the $Y$ axis corresponds to $100 \mathrm{~km} / \mathrm{mol}$. Dash lines correspond to simulated spectra obtained after convolution with a $40 \mathrm{~cm}^{-1}$ FHWM wide Lorentzian profile. The experimental spectrum has been shifted in order to facilitate the comparison.
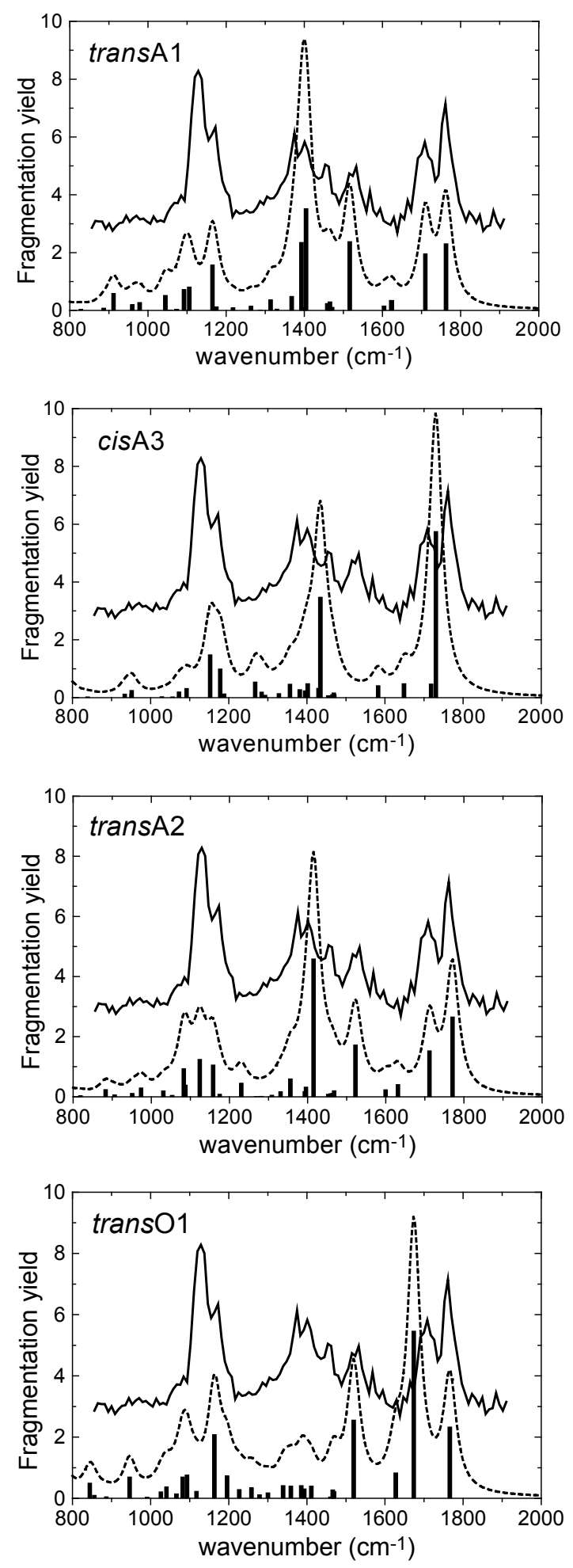


\section{References}

1 J. Laskin, E.Denisov, and J. H. Futrell J.Am.Chem.Soc. 2000, 122, 9703

2 M. J. Polce, D. Ren, and C. Wesdemiotis J.Mass Spectr. 2000, 35, 1391

3 F. Rogalewicz, Y. Hoppilliard, and G. Ohanessian Int. J. Mass Spectroc. 2000, 195, 565

4 J. Laskin and J. H. Futrell J.Chem.Phys. 2002, 116, 4302

5 J. Wang, S. O. Meroueh, Y. Wang, and W. L. Hase Int.Mass Spectr. 230, 57 (2003).

6 I. P. Csonka, B. Paiza, G. Lendway, and S. Suhai, Rapid Comm.Mass Spectr. 14, 417 (2000).

7 V. H. Wysocki, G. Tsaprailis, L. L. Smith, and L. A. Breci, J.Mass Spectrom. 35, 1399 (2000).

8 B. Paizs, I. P. Csonka, G. Lendvay, and S. Suhai, Rap.Comm.Mass Spectr. 15, 637 (2001).

9 A. Schlosser and W. D. Lehmann J. Mass Spectrom. 2000, 35, 1382

10 W. J. Griffiths and A. P. Jonsson, Eur.J.Mass Spectr. 2001, 7, 89

11 J. Lemaire, P. Boissel, M. Heninger, G. Mauclaire, G. Bellec, H. N. Mestdagh, A. Simon, S. L. Caer, J. M. Ortega, F. Glotin, and P. Maitre, Phys.Rev.Lett. 89, 273002 (2002).

12 J. Oomens, G. Meijer, and G. v. Helden J.Phys.Chem.A 2001, 105, 8302

13 Y. P. Ho and R. C. Dunbar Int. J. Mass Spectrom. Ion Processes 1996, 154, 133

14 M. D. Halls, J. Velkowski, and H. B. Schlegel, Theo.Chem.Acc. 2001, 105, 413

15 C. Kapota, J. Lemaire, P. Maître, and G. Ohanessian, J.Am.Chem.Soc. in press (2004)..

16 K. Zhang, D. M. Zimmerman, A. Chung-Phillips, and C. J. Cassady, J.Am.Chem.Soc. 115, 10813 (1993).

17 S. Campbell, M. T. Rodgers, E. M. Marzluff, and J. L. Beauchamp, J.Am.Chem.Soc. 11, 12840 (1995).

18 P. Maitre, S. L. Caer, A. Simon, W. Jones, J. Lemaire, H. N. Mestdagh, M. Heninger, G. Mauclaire, P. Boissel, R. Prazeres, F. Glotin, and J. M. Ortega, Nucl.Instr.Meth. A 507, 541 (2003).

19 W. Jones, P. Boissel, B. Chiavarino, M. E. Crestoni, S. Fornarini, J. Lemaire, and P. Maître, Angw.Chem. 42, 2057 (2003).

20 P. J. Linstrom and W. G. Mallard, in NIST Chemistry WebBook (NIST Standard Reference Database, 2003), Vol. 69.(http://webbook.nist.gov)

21 Gaussian 03, Revision B.04,

M. J. Frisch, G. W. Trucks, H. B. Schlegel, G. E. Scuseria, M. A. Robb, J. R. Cheeseman, J. A. Montgomery, Jr., T. Vreven, K. N. Kudin, J. C. Burant, J. M. Millam, S. S. Iyengar, J. Tomasi, V. Barone, B. Mennucci, M. Cossi, G. Scalmani, N. Rega, G. A. Petersson, H. Nakatsuji, M. Hada, M. Ehara, K. Toyota, R. Fukuda, J. Hasegawa, M. Ishida, T. Nakajima, Y. Honda, O. Kitao, H. Nakai, M. Klene, X. Li, J. E. Knox, H. P. Hratchian, J. B. Cross, C. Adamo, J. Jaramillo, R. Gomperts, R. E. Stratmann, O. Yazyev, A. J. Austin, R. Cammi, C. Pomelli, J. W. Ochterski, P. Y. Ayala, K. Morokuma, G. A. Voth, P. Salvador, J. J. Dannenberg, V. G. Zakrzewski, S. Dapprich, A. D. Daniels, M. C. Strain, O. Farkas, D. K. Malick, A. D. Rabuck, K. Raghavachari, J. B. Foresman, J. V. Ortiz, Q. Cui, A. G. Baboul, S. Clifford, J. Cioslowski, B. B. Stefanov, G. Liu, A. Liashenko, P. Piskorz, I. Komaromi, R. L. Martin, D. J. Fox, T. Keith, M. A. Al-Laham, C. Y. Peng, A. Nanayakkara, M. Challacombe, P. M. W. Gill, B. Johnson, W. Chen, M. W. Wong, C. Gonzalez, and J. A. Pople, Gaussian, Inc., Pittsburgh PA, 2003.

22 R. D. Johnson in NIST Computational Chemistry Comparison and Benchmark Database, Oct. 2003 (http://srdata.nist.gov/cccbdb/) 